\title{
A systematic mapping review of European Political Science
}

\author{
Francisco Mas-Verdu ${ }^{1}$. Jose-Maria Garcia-Alvarez-Coque ${ }^{1}$. \\ Paula Andrea Nieto-Aleman ${ }^{1,2} \cdot$ Norat Roig-Tierno $^{1}$
}

Accepted: 16 November 2020 / Published online: 31 January 2021

(c) European Consortium for Political Research 2021

\begin{abstract}
European Political Science (EPS) has been a leading political science journal since its launch in 2001. This article examines the contribution of European Political Science over its 20-year history. The bibliometric analysis draws on Web of Science data and VOSviewer software. These tools help detect collaboration networks, bibliographic coupling and co-citations to identify the most relevant topics and knowledge appearing in European Political Science. The evaluation of EPS reveals four areas of interest: migration, education, comparative politics and democracy. Recent interests include the current debate on populisms, social media and political parties, with antecedents and implications that transcend national boundaries.
\end{abstract}

Keywords Bibliometrics · Political science - Vosviewer - Web of science

\section{Introduction}

This article analyses the contribution of European Political Science (EPS) to the field of political science throughout the journal's 20-year history. The analysis consists of the systematic study of the documents that the journal has published. This type of analysis offers a critical evaluation of the journal's development over these past 20 years. What is the journal's history? How has the journal evolved? This in-depth analysis of EPS articles, the institutions whose scholars submit their research to the journal,

Norat Roig-Tierno

norat.roig@upv.es

Francisco Mas-Verdu

fmas@upvnet.upv.es

Jose-Maria Garcia-Alvarez-Coque

jmgarcia@upvnet.upv.es

Paula Andrea Nieto-Aleman

paunieal@upv.es

1 Universitat Politècnica de València, C/Vera, Valencia, Spain

2 ESIC Business and Marketing School, C/Blasco Ibañez, Valencia, Spain 
the key authors and the impact of their research can help identify potential areas for improvement.

Bibliometrics is a valuable tool for the qualitative analysis of a field of study such as management (Podsakoff et al. 2008), innovation, entrepreneurship (Landström et al. 2012) or psychology (Tur-Porcar et al. 2018). Journals with a recognized academic history usually have systematic reviews and a critical appraisal of their past in order to assess their future trajectory. Bibliometrics is useful for in-depth analysis of a particular journal, providing an overview of the leading trends for that journal. The first article presenting bibliometric analysis of a journal was by Heck and Bremser (1986). This article focused on the evolution of the Accounting Review over its 60-year history. In the present article, we use bibliometrics to identify the key features of EPS in terms of future developments in the field of political science. It is not our goal to conduct an overall comparison of all political science journals; other articles already provide such analysis (Hix 2004; Giles and Garand 2007). Instead, our goal is to explore the specific positioning of EPS and its contribution to this field of study. In doing so, we will, of course, have to refer to other journals in the field.

We use mixed methods to pursue this aim from two perspectives. First, we analyse the indexed documents in the leading scientific research repository, namely the Web of Science (WoS). This analysis relies on bibliometric techniques. Second, we use VOSviewer software to map collaboration networks, bibliometric coupling and co-citations. This mapping analysis reveals the most relevant topics and knowledge appearing in EPS.

Using this analysis, we answer the following research questions: What topics and articles have received the most attention from the scientific community? What topics have had the greatest impact and the most influence? How have these topics developed over time? Which authors, institutions and countries have had the greatest impact on EPS? What do the EPS collaboration networks look like?

This analysis reveals the theoretical and practical approaches appearing in EPS, as well as the methods that authors have applied. Specifically, we analyse patterns, clusters and co-occurrence structures from a multidimensional perspective. These two approaches offer a holistic view of the contribution of EPS to the field of political science over the journal's 20-year history. This article concludes by proposing a research agenda for policymakers and EPS readers.

This article has the following structure. "Political science and EPS" section describes EPS and states our research aims. "Method" section defines the method for the bibliometric analysis. "A journey through the history of EPS" section describes the results of the bibliometric analysis of leading authors, institutions and countries (using WoS data) and presents the results of the co-citation and bibliographic coupling analysis (using VOSviewer software). Finally, "Conclusion" section offers a discussion and proposes a research agenda. 


\section{Political science and EPS}

Political science research covers a wide range of topics. Examples include public opinion (Burstein 2010; Stimson 2019), politics and the gender gap (Kaufmann 2006; Howell and Day 2000; Kellstedt et al. 2010; Mendelberg et al. 2014), human rights oppression (Leblang et al. 1999; Shor et al. 2014; Donnelly 2020), law enforcement and its effects (Heise 2002; Møller and Skaaning 2013; Gratton and Lee 2020; Oztig and Donduran 2020), and the political control of bureaucracy (Meier and O'Toole 2006; Ahn, and Bretschneider 2011; Dahlström and Holmgren 2019; Bach et al. 2020). In recent years, an international focus in this discipline has gradually begun to replace and complement the predominant national focus. This shift has occurred because whilst many political problems arise within a local context, they also have global antecedents and implications.

The need for an international community of scholars was behind the foundation of the European Consortium for Political Research (ECPR) in 1970. The ECPR launched its professional journal journal, European Political Science (EPS), in 2001. The journal emerged from ECPR News in 2001, before moving to Palgrave Macmillan in 2005. The contributions in this discipline span the fields of comparative politics, political economy, international relations, public administration, political theory, European studies and other similar disciplines. The articles appearing in this journal focus not only on European affairs and the development of political science per se but also on comparisons between European politics and politics in other regions and countries. The journal's aim is thus to attract interest from political scholars and practitioners around the world.

\section{Method}

The analysis in this study draws upon two data sources: The Web of Science (WoS) database and the EPS website. Specifically, EPS has published 1,032 articles since 2001. The WoS has indexed 825 of these articles since 2008, the year in which EPS first appeared in the WoS database.

We use WoS data because this database covers most of the volumes of EPS (79.9\% of articles). Furthermore, the WoS is the leading academic database (López-Rubio et al. 2020). We gathered the data in September 2020 from the Core Collection database.

This bibliometric analysis of EPS offers a thought-provoking case study that reflects how the political science arena has evolved in the last few decades. Narin (1976) reported that large scientific institutions are publishing many highly cited articles in highly influential journals. The evidence suggests that truly creative scientists who publish frequently receive a higher number of citations and contribute to the advancement of science to a far greater extent than the average scientist. Consequently, the technique of bibliometrics enables an initial assessment of the role of EPS, as well as analysis of how the main topics in political science 
have evolved. In recent years, bibliometric studies have focused on the growth of research in different areas of knowledge (Chiu and Ho 2007; Bornmann and Mutz 2015; Mas-Tur et al. 2019; Sarin et al. 2020). The social sciences represent a common target for this type of analysis (De Bakker et al. 2005; Chao et al. 2007; Mora et al. 2017; López-Rubio et al. 2020).

In this study of key bibliometric indicators, we use VOSviewer (van Eck et al. 2007, 2010) software to analyse WoS data and perform analysis of bibliometric coupling, cocitations and clusters. Through science mapping and the use of performance indicators in terms of productivity and relevance, these empirical techniques reveal who collaborates with whom and show how the journal's main topics have evolved over time.

Because EPS serves the political science community, one measure of its impact is the number of articles it publishes. However, given that EPS focuses not only on European affairs but also on issues of political science in other continents, it is perhaps of greater interest to examine the number of citations in relevant journals and the influence of certain authors, institutions and countries. One way of evaluating influence is to examine the research network participation of those who have authored articles appearing in EPS. It is also of interest to consider the nature and quality of the citing institutions. According to the EPS aims and scope, its interpretation of political science is wide. Therefore, we study the variety of focal topics and the way in which these topics have evolved over time. This analysis covers the topics within the journal's scope, including comparative studies, political economy, international relations, public administration, political theory, European studies and related disciplines. Specifically, we answer the following seven research questions:

- RQ1: How have the figures for the number of articles published in EPS and the number of citations of these articles evolved over time?

- RQ2: What articles have received the most attention from the scientific community?

- RQ3: Which authors, institutions and countries have had the greatest impact on EPS?

- RQ4: What do the EPS collaboration networks look like?

- RQ5: Who is citing EPS and where?

- RQ6: What theoretical knowledge do contributors share in EPS?

- RQ7: What topics have the greatest impact and the most influence?

For each research question, we discuss (i) the pertinence of the research question, (ii) the method to answer the question, (iii) the interpretation of the research question in terms of the scope and impact of EPS, and (iv) other issues such as political science trends, the qualitative and quantitative positioning of EPS amongst journals of a similar scope, and other specific journal features.

\section{A journey through the history of EPS}

RQ1: How have the number of articles published in EPS and the number of citations of these articles evolved over time? 
The number of published articles is a measure of how much the members of the political science community have used EPS as a way of communicating their results or exchanging their views. The number of citations is a measure of quality in terms of citations in journals in the Web of Science database. The WoS supplies these measures. The moment when the WoS indexed EPS is also of interest. Figure 1 shows the evolution of the number of documents appearing in EPS and the number of citations they have received. Figure 1 also shows the number of publications in the WoS.

Figure 1 shows that the WoS has indexed EPS since 2008. Since then, the WoS has indexed 825 documents out of 1,032 appearing in the journal. These 825 documents consist of 427 articles, 178 book materials, 144 editorial materials, 63 reviews, seven biographical items and seven corrections. We present the subsequent analysis for the 427 articles and 144 editorial materials (571 documents in total). This collection of texts reflects the different forms of expression that the journal welcomes. Interestingly, it was not until 2008 that the WoS indexed EPS. The academic community often refers to a "Death Valley" in scientific journals, which refers to the fact that a journal has to attract readers and citations before the WoS considers it worthy for indexation. Once the WoS had indexed EPS, the journal became even more attractive for potential authors because of this endorsement of its quality. During the period between January 2008 and September 2020, EPS articles received 2,270 citations. Figure 1 shows the evolution of these citations. The trend is increasing, reflecting the attention that EPS is receiving within the academic community. In terms of the WoS impact factor, the position of EPS in relative terms has shifted between Q3 and Q2 (third and second quartiles) since 2013. It was ahead of 50 per cent of all "Political Science" journals in the years 2013, 2016 and 2019.

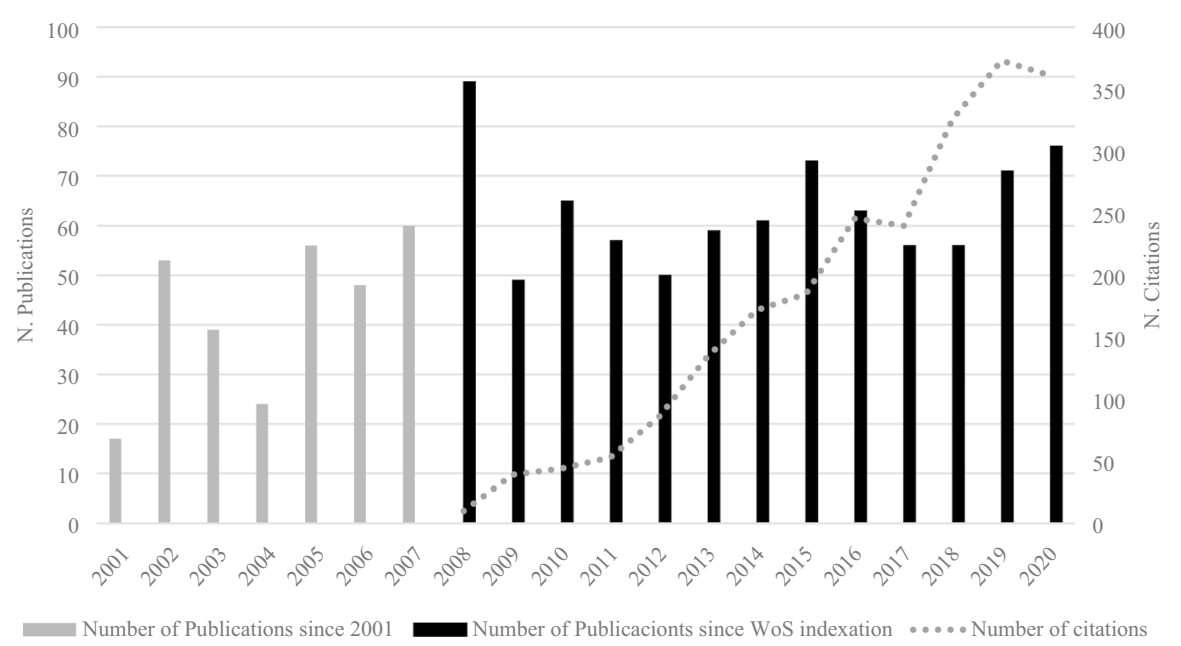

Fig. 1 Number of articles appearing in EPS and citations over time 
The second research question (RQ2) is as follows: What articles have received the most attention from the scientific community?

The measures we use to answer RQ1 provide an initial measure of the interest that EPS has attracted amongst the political science community. To answer RQ2, we consider a small group of specific articles with the greatest impact. They reflect influential articles in the history of EPS. Again, the WoS provides the two indicators we use to define the most relevant articles appearing in EPS. These articles appear in Table 1, which contains articles meeting one of the following criteria: the first ranking (R1) shows the most cited articles (at least twenty-five citations); the second ranking (R2) shows recently published articles (2019 and 2020) that have received more than three citations. R1 refers to the total number of cites since the creation of the journal. R2 refers to the most recently published articles. Thus, R1 relates to core articles, whereas $\mathrm{R} 2$ relates to articles with instant impact, although we do not yet have any indication of their medium-term impact.

The most cited article, "An outline of the bibliometric indicator used for performance-based funding of research institutions in Norway" (Ranking 1), is by Schneider (2009). This article has sixty-five citations in the WoS. This research discusses a bibliometric indicator for performance-based funding of the "Norwegian model" (Sivertsen 2006). It therefore relates to research institutions in Norway. The author uses the Web of Knowledge (now Web of Science) to analyse publications in Norwegian institutions. Interestingly, the bibliometric technique that the author used in that study is an antecedent of the methods that we employ in the present study. The use of this technique to analyse a European country's research performance was a novel approach in 2009. The article also reflects the openness of EPS to institutional evaluation.

The other highly cited articles cover a wide range of aspects that relate to the theory of democracy, deliberation, institutionalism and European strategies. Some authors are influential in their fields. Examples include Marc Helbling (migration and political conflicts), P.A. Hall (process tracing in political science), Jurg Steiner (deliberative politics) and Marc Bühlman (democracy barometers). The article by Helbling et al. (2017), "Measuring immigration policies: the IMPIC database", has received thirty-one citations in 3 years. The study was original in that it used new data sets to systematically measure immigration policies and bilateral migration flows for OECD countries, showing that they are able to control their borders through immigration policies.

The R2 list refers to recent developments in European politics. Examples include the rise of populist movements and the surge in authoritarianism. In a sense, the journal achieves an impact when its articles refer to grassroots concepts in political science or study antagonistic discourses and crises in modern democracies. The article with the highest number of citations per year, "Reversing regimes and concepts: from democratization to autocratization", is by Cassani and Tomini (2020). The phenomenon of populism has attracted intense attention from the scientific community. Articles such as "Social media populism: features and 'likeability' of Lega Nord communication on Facebook" by Bobba (2019) and "The populism/anti-populism frontier and its mediation in crisis-ridden Greece: from discursive divide to 


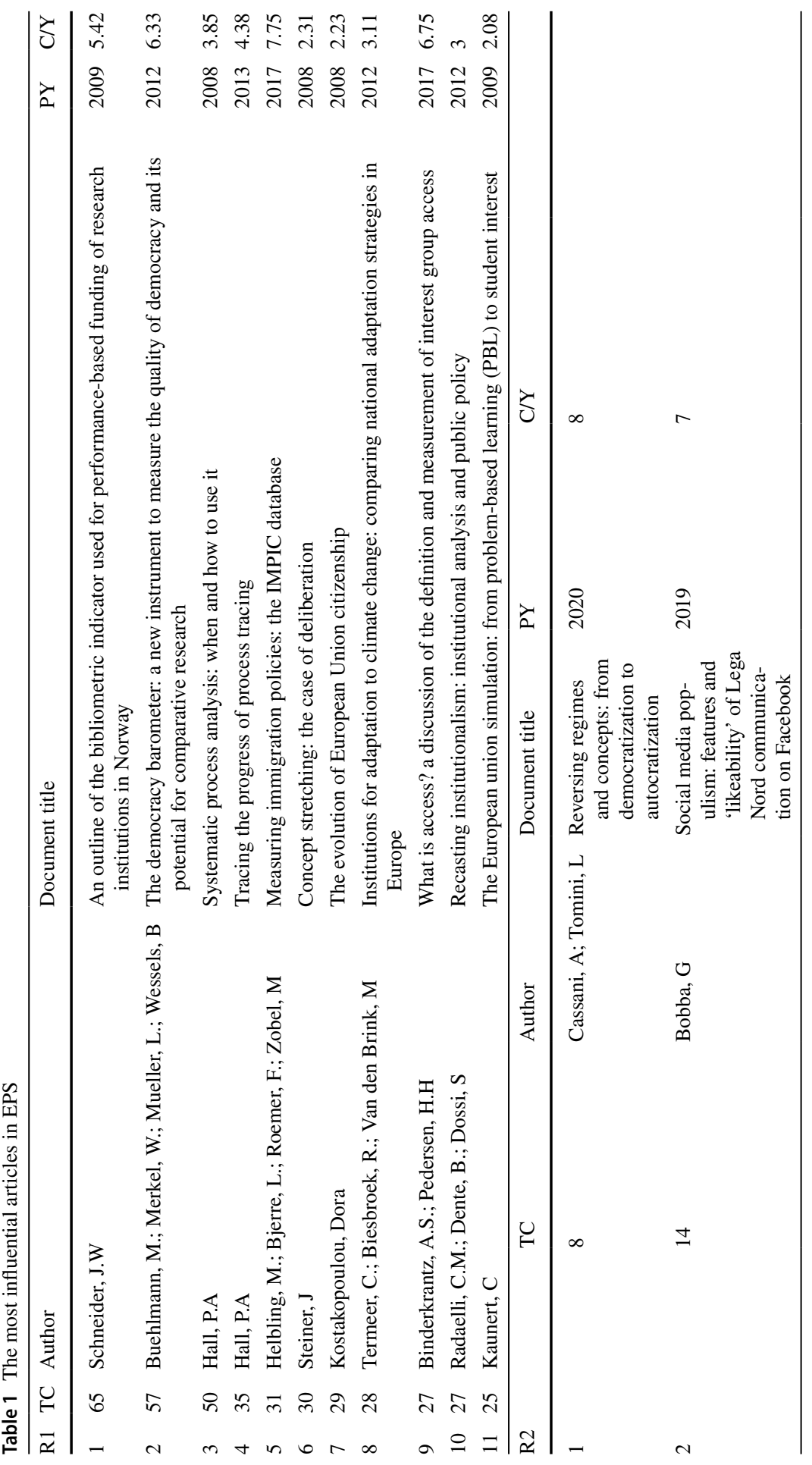




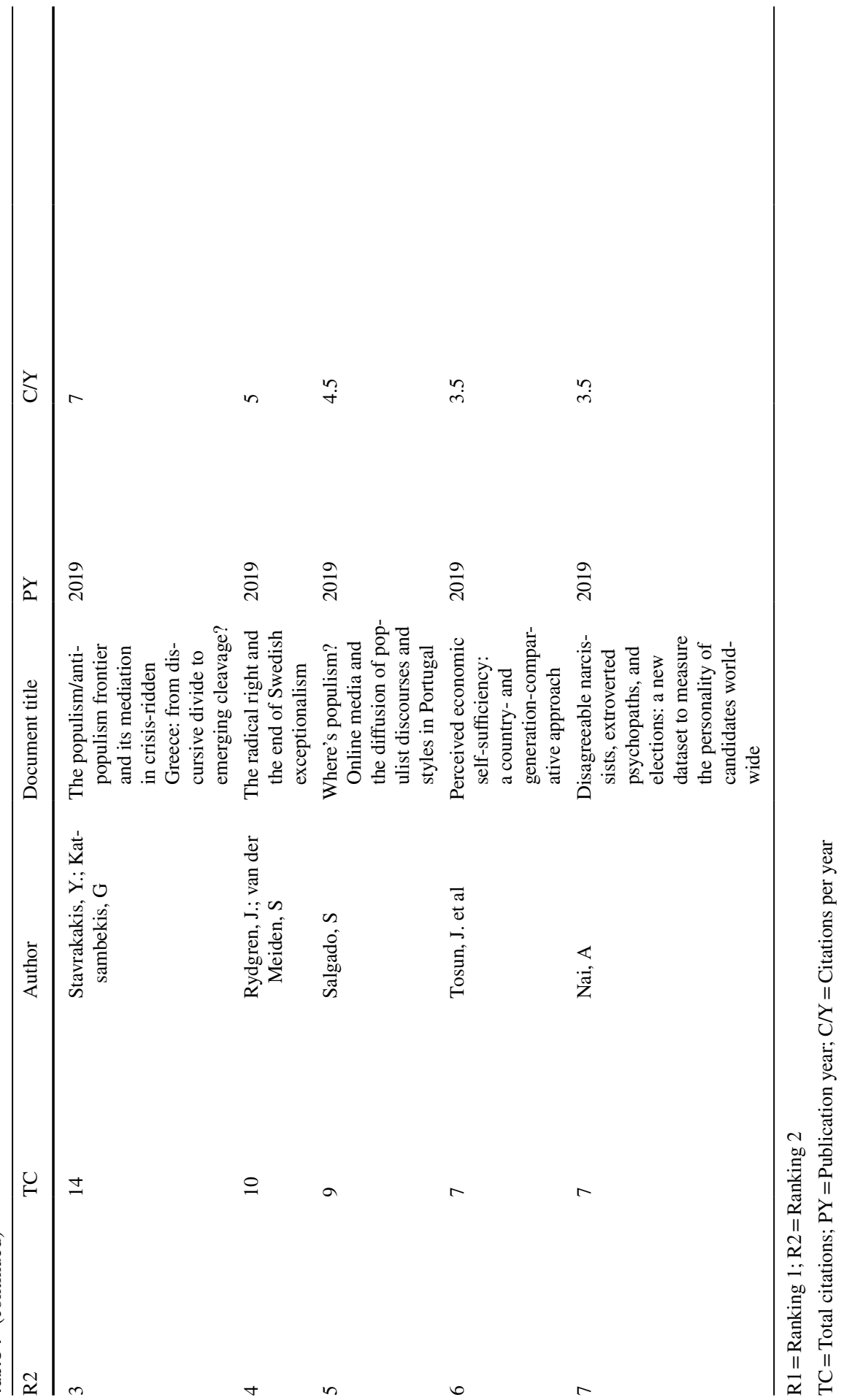

站。 
emerging cleavage?" by Stavrakakis and Katsambekis (2019) reflect this attention. The latter article not only explores the recent surge of populism but also offers an in-depth analysis of the recent process in Greece, reflecting a complex choreography between populism and anti-populism reactions and discourses. The geographical coverage of the most recent highly cited articles is expanding, opening the debate on current crises in modern democracies across Northern and Southern Europe.

The next research question refers to the impact on EPS. RQ3: Which authors, institutions and countries have had the greatest impact on EPS?

Though less specific than RQ2, RQ3 focuses on the research groups, institutions and countries that have relied on EPS to communicate their political science contributions. The WoS provides this information and links it to several performance indicators. WoS data refer to the position of the corresponding institution in university rankings such as the Academic Ranking of World Universities (ARWU) and Quacquarelli Symonds (QS). These sources reveal whether leading universities use EPS as an outlet for their research.

Table 2 shows the most productive and influential authors in EPS. This table includes articles that the WoS has indexed since 2008. The most productive author is M. Bull from the University of Salford, with eleven studies published in EPS. Regarding the number of citations, four authors have more than twenty citations: Curtis (thirty-three citations), Gherghina (thirty-one citations), Blair (twenty-six citations) and Craig (twenty-two citations). These citations only correspond to studies appearing in EPS. The most productive female author is Heather Savigniy, whose main topic of interest is women in political science. Teele and Thelen (2017: 433) report that "most published collaborative research in these journals emerges from all-male teams", which could explain this result, which is in line with the publications by Stockemer et al. (2020) that state that there are twice male authors that

Table 2 The most productive and influential authors in EPS

\begin{tabular}{llllrrrr}
\hline R & Author & Affiliation & Country & TS & TC & h & C/S \\
\hline 1 & Bull, M & U. of Salford & UK & 11 & 12 & 2 & 1,09 \\
2 & Stockemer, D & U. of Ottawa & Canada & 8 & 17 & 2 & 2,13 \\
3 & Blair, A & De Montfort U & UK & 7 & 26 & 3 & 3,71 \\
4 & Gherghina, S & U. of Glasgow & UK & 6 & 31 & 2 & 5,17 \\
5 & Qvortrup, M & Coventry U & UK & 5 & 6 & 1 & 1,20 \\
6 & Savigny, H & De Montfort U & UK & 5 & 13 & 3 & 2,60 \\
7 & Buckley, F & U. College Cork & UK & 4 & 12 & 2 & 3,00 \\
8 & Craig, J & Leeds Beckett U & UK & 4 & 22 & 3 & 5,50 \\
9 & Curtis, S & London Metropolitan U & UK & 4 & 33 & 4 & 8,25 \\
10 & De Sousa, L & U. of Lisbon & Portugal & 4 & 10 & 3 & 2,50 \\
11 & Kuehn, D & U. Heidelberg & Germany & 4 & 17 & 3 & 4,25 \\
\hline
\end{tabular}

The authors in this list have published four or more articles in EPS. $\mathrm{R}=$ ranking; TS $=$ total studies; $\mathrm{TC}=$ total citations $\mathrm{h}=\mathrm{h}$-index $; \mathrm{C} / \mathrm{S}=$ citations per study 
submit articles to EPS, while this difference decrease considerably when it comes to the publication stage. Actually, past and current power structures might explain the poor gender balance in the publication record. This finding is a matter of reflection for the future of the editorial policy of EPS. The gender gap in political science, as well as the need for gender studies, has received attention (Bates et al. 2012; Bates and Savigny 2015; Evans and Amery 2016). The EPS publication record reflects this need.

UK universities are the most productive and influential institutions in EPS. The leading UK universities are the University of London, the University of Salford, De Montfort University, the University of Birmingham, the University of Bristol and the University of Huddersfield. The University of London tops the ranking, with twenty-three studies and 101 citations (Table 3). This result is understandable, considering that the University of London is a federal university with several independent member institutions. Most of the other highly ranked universities are from continental Europe. Despite the strong presence of UK institutions in EPS, the author structure in the journal is spread across Western European institutions. The representation of Central and Eastern Europe authors is low. However, the representation of North American scholars is even lower, with a few exceptions in some Canadian and U.S. universities. The most prominent institutions in EPS generally have high international rankings. Four of the top twelve universities (Table 3) are inside the ARWU's top 100 research universities. Five of the top twelve universities are inside the top 100 of the QS World University Ranking, which measures reputation from a teaching and employability perspective.

One explanation for the dominant presence of UK institutions is that the UK continues to be a leading hub for professional associations (e.g. ECPR and UACES). Moreover, the UK PSA is the second largest professional political association in the world. Nevertheless, the fact that many of the highly cited articles in recent years

Table 3 The most productive and influential institutions in EPS

\begin{tabular}{lllrrrrrl}
\hline $\mathrm{R}$ & Institution & Country & $\mathrm{TS}$ & $\mathrm{TC}$ & $\mathrm{h}$ & $\mathrm{C} / \mathrm{S}$ & ARWU & QS \\
\hline 1 & U. of London & UK & 23 & 101 & 6 & 4,39 & 15 & 8 \\
2 & European U. Institute & Italy & 19 & 44 & 4 & 2,32 & - & - \\
3 & U. of Salford & UK & 12 & 36 & 3 & 3 & - & $801-1000$ \\
4 & U. of Lisbon & Portugal & 10 & 28 & 3 & 2,8 & $151-200$ & 357 \\
5 & U. of Ottawa & Canada & 9 & 35 & 3 & 3,89 & $151-200$ & 279 \\
6 & De Montfort U & UK & 8 & 21 & 3 & 2,63 & - & $801-1000$ \\
7 & Leiden U & Netherland & 8 & 19 & 2 & 2,38 & 80 & 128 \\
8 & Heidelberg U & Germany & 8 & 35 & 4 & 4,38 & 57 & 64 \\
9 & U. Birmingham & UK & 7 & 33 & 4 & 4,71 & $101-150$ & 87 \\
10 & U. Bristol & UK & 7 & 29 & 4 & 4,14 & 64 & 58 \\
10 & U. of Amsterdam & Netherland & 7 & 28 & 4 & 4 & $101-150$ & 61 \\
10 & U. Huddersfield & UK & 7 & 24 & 3 & 3,43 & - & $701-750$ \\
\hline
\end{tabular}

$\mathrm{R}=$ ranking; $\mathrm{TS}=$ total studies; $\mathrm{TC}=$ total citations $\mathrm{h}=\mathrm{h}$-index $\mathrm{C} / \mathrm{S}=$ citations per study; $\mathrm{ARWU}=\mathrm{Aca}-$ demic Ranking of World Universities 2020; QS = Quacquarelli Symonds University Ranking 2020 
(see RQ2) are by scholars from institutions outside the UK shows an increasingly cosmopolitan tendency in political science. This finding also reflects the trend of journals that focus on comparative politics and international relations, as Garand and Giles (2003) note.

RQ4: What do the EPS collaboration networks look like?

A journal's strength also depends on the alliances and collaboration networks that the journal is able to foster. Leading research institutions collaborate with authors and institutions from inside or outside their regions or countries and form wide geographical networks (Huggins et al. 2019). VOSviewer helps identify the collaboration networks amongst EPS authors according to the co-occurrence of authors in EPS articles. Co-authorship is the most common way to measure collaboration.

Figure 2 shows the network of collaborating authors in EPS. The network shows small groups of authors collaborating in related topic areas. The EPS publication record reflects a bias in political science towards individual contributions. Only two collaboration clusters emerge. Cluster 1 consists of Blair, Stockemer, Curtis and Buckley. This cluster highlights the relationships within the EPS editorship: Blair and Stockemer are Editors, and Buckley is the Reviews Editor. Cluster 2 comprises Bates, Savigny and Williams. Heather Savigny is also a member of the Editorial Board of EPS. Both clusters are from UK institutions and contain many of the most productive authors. This finding raises the question of whether EPS should increase its promotion of interdisciplinary and international collaborations.

RQ5: Who is citing EPS and where?

Is EPS a valuable source within the political science community and related disciplines? We study this question by measuring not only the number of citations (RQ1) but also the fields of the citing journals and institutions. The WoS classifies journals by their main field. Therefore, we can use this database to explore the characteristics of the citing community. To identify who is citing EPS research, we analyse citations in the WoS (number of citations of the 571 selected documents). EPS has received more than 1,600 citations from different disciplines. Figure 3 shows that EPS articles have received citations from more than nineteen fields. Three out of every four citations come from three main disciplines: Political Science (53.2\%), International Relations (14.7\%) and Public Administration (7.8\%). The fact that these disciplines represent around $75 \%$ of the citing journals suggests that the focus of EPS is clear to its readers. However, Fig. 3 suggests that the scope of interest covers a large readership from diverse areas, including education, sociology, economics and environmental studies.

More than 820 journals have cited EPS articles. Therefore, regardless of their number, these citations correspond to a wide range of articles. Figure 4 shows the top twenty journals citing EPS articles. The journals citing EPS articles form three categories: Category 1 is "European Politics", including journals such as Journal of European Public Policy, West European Politics and Journal of European Integrations; Category 2 is "Political Science", including journals such as PS: Political 
craig, j

gherghina, s

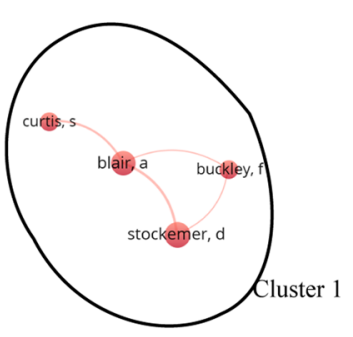

kuehn, d

croissant, a

schneider, $g$

adriaensen, $\mathrm{j}$

hooghe, $m$

woodcock, p

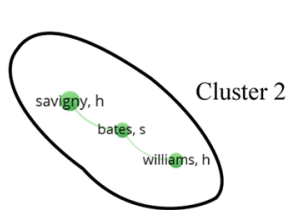

qvortrup, $m$

de sousa, I

kennealy, $\mathrm{p}$ radaelli, $\mathrm{cm}$

bellamy, $r$

hamenstaedt, u

\section{bull, mj}

Fig. 2 Co-authorship map of authors. Note: Minimum number of documents per author: $3 ; 28$ of the 757 authors meet this threshold

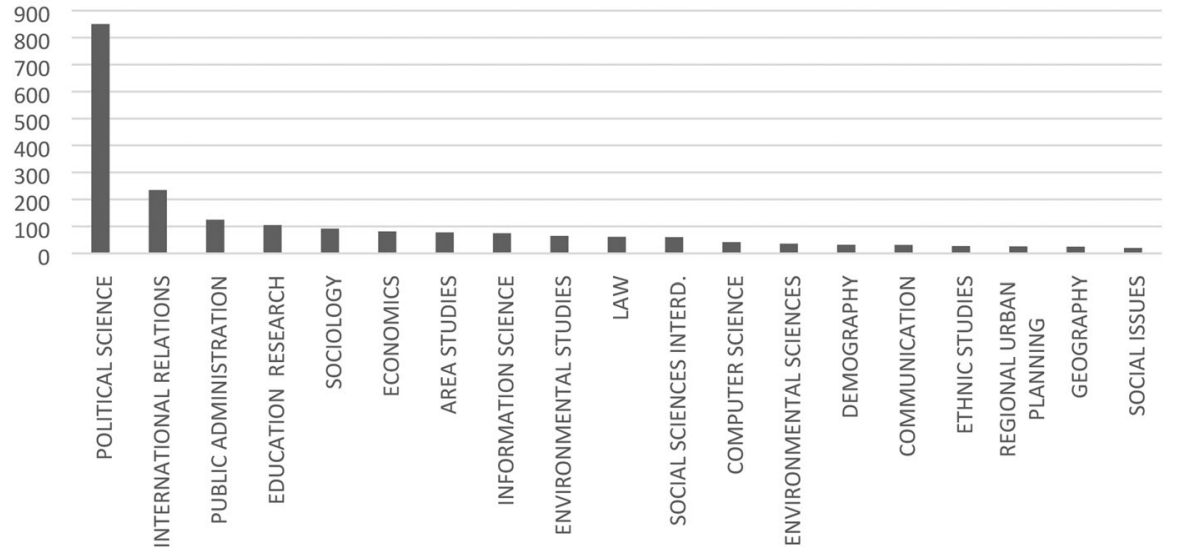

Fig. 3 Citation categories

我的 
Science \& Politics, Political Studies Review and Contemporary Politics; and Category 3 is "Interdisciplinary", including journals such as Scientometrics and Research Evaluation. Seven of the top ten citing journals are in either Q1 or Q2 in their area. The two interdisciplinary journals are from the area of information science. The most cited article (Schneider 2009) is from this field. This finding suggests that current and potential readers appreciate interdisciplinary categories such as those that relate to the evaluation of European research and educational institutions.

RQ6: What theoretical knowledge do authors share in EPS?

On which topics, concepts or issues does EPS contribute to political science knowledge? We use co-citations and bibliographic coupling analysis in VOSviewer to answer RQ6. According to Suominen et al. (2019), co-citation analysis provides a historical view of the origins of a topic or journal (in this case, EPS), whereas bibliographic coupling analysis provides a contemporary view. Bibliographic coupling occurs when two documents have the same citing documents (Kessler 1963). For example, bibliographic coupling occurs when documents A and B cite document $X$. Figure 5 shows four clusters with more than fifteen items. The number of items refers to the number of articles that share references. We can analyse the main cluster and link it to the most cited article in the cluster (Table 4).

Table 4 shows the most relevant topics in the thematic analysis of the four main clusters. Cluster 1 consists of articles that relate to immigration policies. However, it also includes articles on religion and institutionalism. Cluster 2 focuses on active learning, teaching, the promotion of education in EU counties and political education. Cluster 3 contains different methodological approaches and case studies

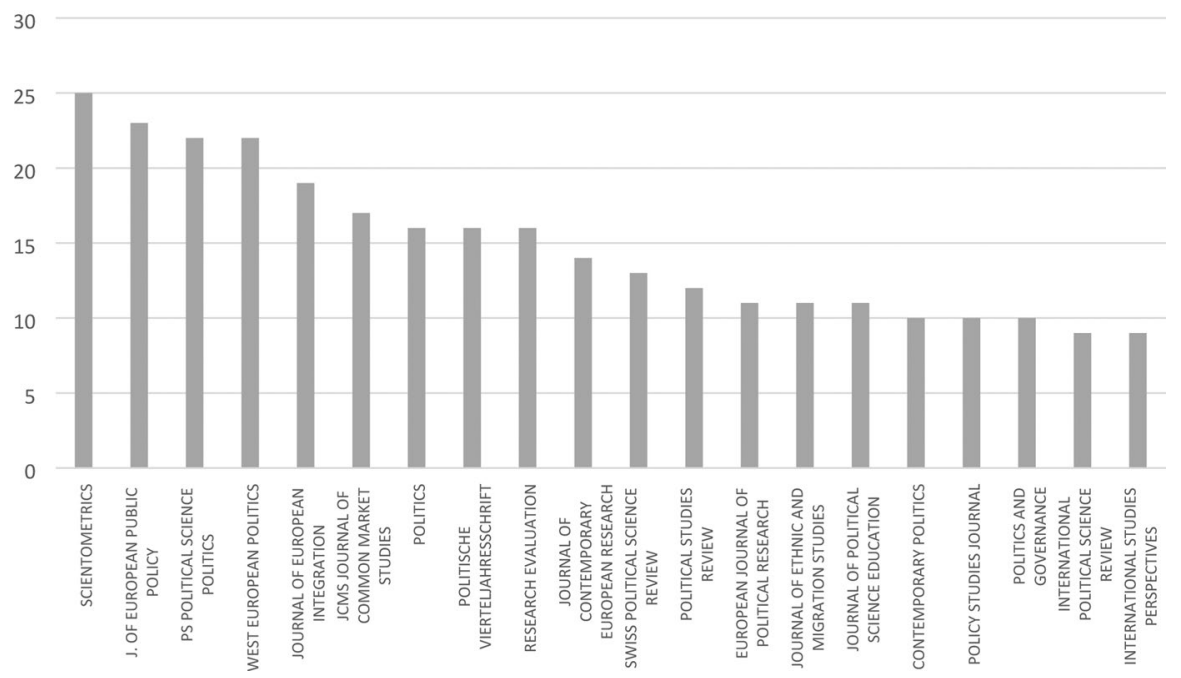

Fig. 4 Top twenty journals citing EPS articles. Note: We excluded EPS from the list. EPS self-citations account for $9.4 \%$ 


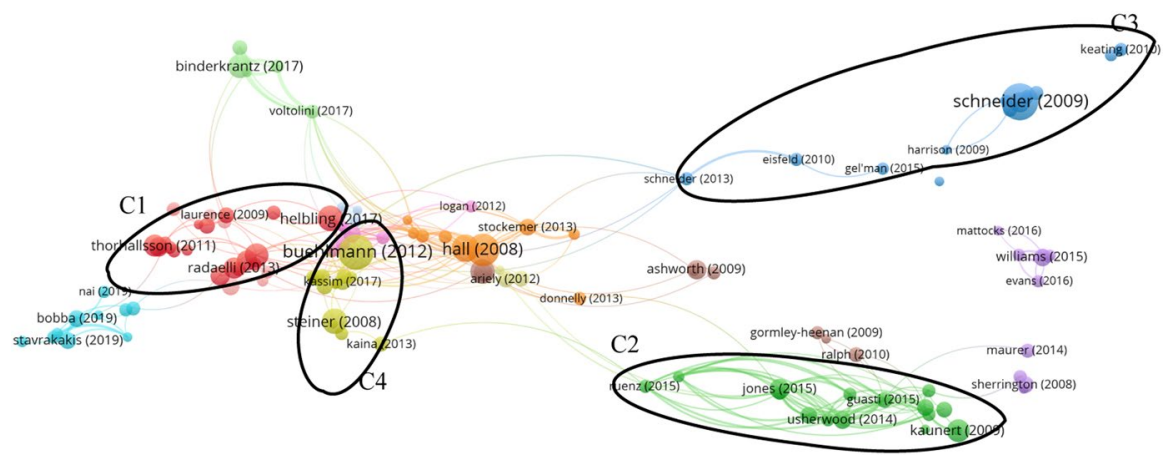

Fig. 5 Bibliographic coupling analysis. Note: Minimum number of citations per document: 5; 163 of the 571 documents meet this threshold

such as France, Finland and Norway. Finally, Cluster 4 relates to democracy and governance.

Figure 6 and Table 5 complement the data on knowledge clusters in EPS. They show the most cited authors of EPS articles in each cluster. Again, the citation network is diverse and reflects the core references in each cluster. Predictably, official documents by the European Commission are a key source of data and political information.

RQ7: What topics have had the greatest impact and the most influence?

This research question refers to the topics that have attracted, and will perhaps continue to attract, the most attention in the publishing record of EPS. To answer RQ7, we analyse the key concepts in the articles appearing in EPS and study how these concepts have evolved over time (Fig. 7). VOSviewer builds these networks using keywords in EPS articles. Each colour in the network of key concepts denotes the period since the early 2010s when a given concept was most prominent.

As Fig. 7 shows, in the first few years of the 2010s, EPS focused on topics that related to governance, European studies and the Bologna Process. Keywords such as "United States" and "financial crisis" were of particular interest, reflecting the European political responses to the international economic crisis. In subsequent years, topics that related to political science, democracy, international relations and higher education became more prevalent. This shift shows the consolidation of the

Table 4 Relevant contemporary thematic clusters

\begin{tabular}{llll}
\hline Cluster & Number of items & Key contribution in the cluster & Topic \\
\hline 1 & 19 & Helbling et al. (2017) & Migration policies \\
2 & 16 & Kaunert (2009) & Education policies \\
3 & 16 & Schneider (2009) & $\begin{array}{c}\text { Comparative politics, met- } \\
\text { rics and scientometrics }\end{array}$ \\
4 & 16 & Bühlmann et al. (2012) & Democracy and governance \\
\hline
\end{tabular}




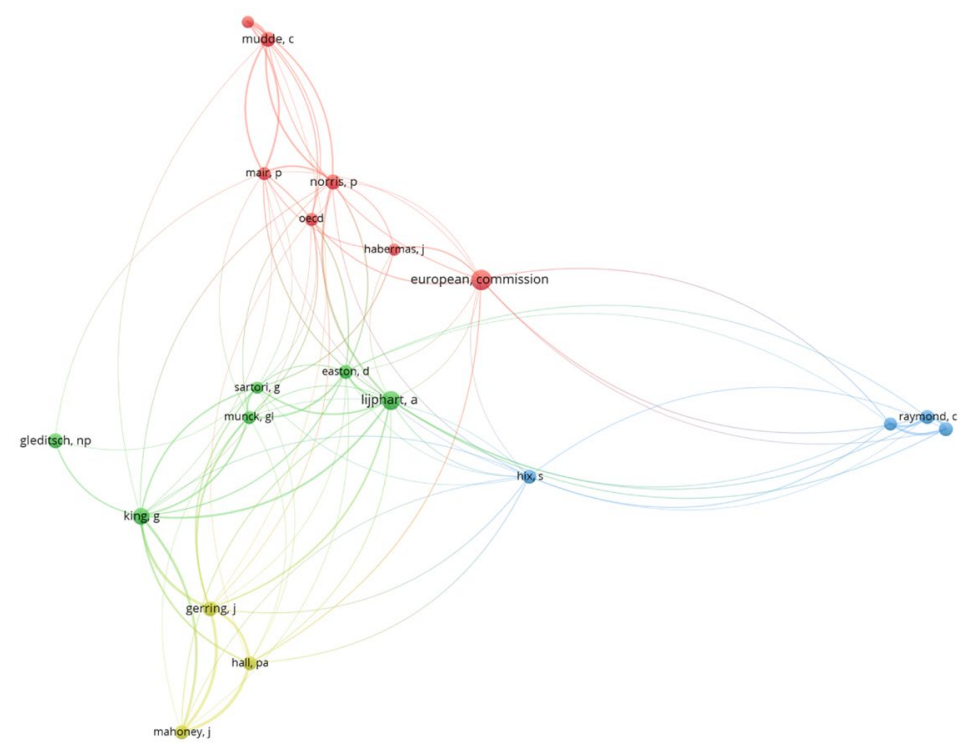

Bosviewer

Fig. 6 Co-citation analysis of cited authors. Note: Minimum number of citations per author: 20; 20 of the 9,146 authors meet this threshold

Table 5 Author clusters

\begin{tabular}{|c|c|c|}
\hline $\begin{array}{l}\text { Cluster } \\
\text { number and } \\
\text { colour }\end{array}$ & Authors in the cluster & Label \\
\hline $1-\operatorname{Red}$ & $\begin{array}{l}\text { European Commission; Habermas; Mair; } \\
\text { Mudde; Norris; OECD; Rydgren }\end{array}$ & Europe and the radical right in Europe \\
\hline 2 -Green & $\begin{array}{l}\text { Easton; Gleditsch; King; Lijphart; Munck; } \\
\text { Sartori }\end{array}$ & Comparative method \\
\hline 3 -Blue & Asal; Hix; Raymond; Usherwood & Education and active learning \\
\hline 4-Yellow & Gerring; Hall; Mahoney & Institutionalisms and qualitative research \\
\hline
\end{tabular}

four knowledge clusters emerging in response to RQ6, with an increasing focus on educational issues and gender. In the last few years, EPS has focused on the main challenges in Europe, such as populism, anti-populism, the far right, immigration and the diversification of geographical attention towards Southern Europe. The central keywords are still political science, Europe, democracy and politics. 

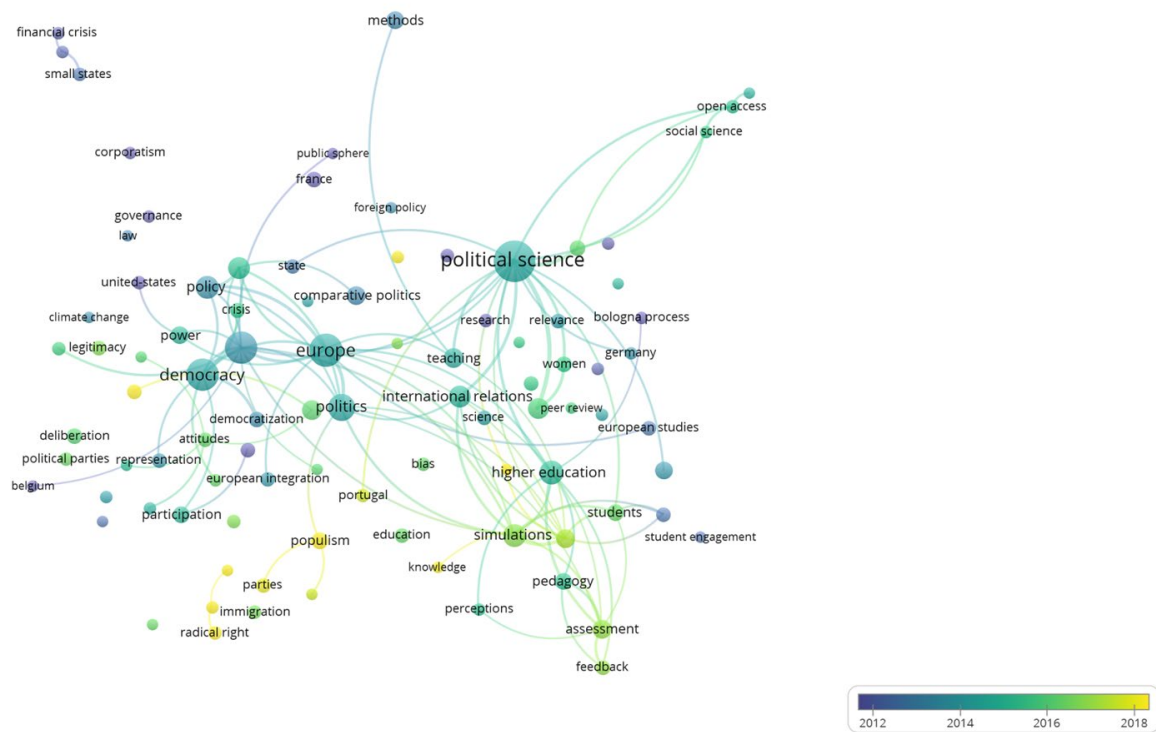

Fig. 7 Key concepts in EPS. Note: Minimum number of occurrences of a keyword: 5; 95 of the 1,757 keywords meet the threshold

\section{Conclusion}

\section{Discussion of the current research agenda}

Academics worldwide are constantly enriching and updating our understanding of politics and governance. Empirical research on politics not only satisfies our natural human curiosity but also provides analysis of political conditions around the world. New ways of studying politics and new statistical methods encourage the advent of new theories in the political sciences (Johnson et al. 2015).

This study provides an overview of the leading authors, institutions and countries in terms of research appearing in EPS. The number of articles appearing in EPS has more than doubled over the last two decades. The goal of our analysis is to determine which authors, institutions and countries have had the greatest influence due to the articles that have appeared in EPS. We use bibliographic data from the WoS Core Collection database and apply a mix of descriptive and graphical analyses.

In recent years, EPS publications have received an increasing number of citations. Possible reasons for this increase include (i) a core focus on political science along with a diversification into several other fields and an increasingly interdisciplinary approach, (ii) an adaptation of the scope of EPS to contemporary issues, without a loss in methodological rigour and relevance, (iii) a 
growing interest in teaching and education studies, with reference to institutional evaluation.

Considering the most recent high-impact articles can shed light on the broad scope of EPS and the current interests in political science. In "Reversing regimes and concepts: from democratization to autocratization" by Cassani and Tomini (2020), the authors highlight the difficulties surrounding "autocratization", especially regarding the empirical threshold for identification of an outright regime change. Bobba (2019) centres on the key features of nationalist parties, namely the existence of a charismatic leader and the role of social media.

Along similar lines in relation to popularism, Stavrakakis and Katsambekis (2019) explore how all parties under populism or anti-populism follow framing techniques in "The populism/anti-populism frontier and its mediation in crisisridden Greece: from discursive divide to emerging cleavage?" Salgado (2019) also explores the role of social media in "Where's populism? Online media and the diffusion of populist discourses and styles in Portugal". Finally, in "Disagreeable narcissists, extroverted psychopaths, and elections: a new dataset to measure the personality of candidates worldwide", Nai (2019) advocates further study of the elections that have taken place worldwide since March 2018 (Nai 2019). Comparisons and in-depth analyses of personality, campaigning, the media and electoral dynamics are necessary.

Many of these studies focus on specific regions or types of parties. To provide more generalizable results, future studies should focus on comparative samples. Recent changes in international politics suggest that North American and European politics, to name but two regions, have strong links, both conceptually and factually. We respond to the challenge of presenting some key questions for the research agenda. The COVID-19 pandemic will heavily affect this research agenda. However, it should address the climate challenges that the research agenda in this field has thus far overlooked. Emerging points of the research agenda might include the following:

(i) What is the role of far-right parties in Europe? What is the stance of the formal and informal institutions towards them? Research should include discourse analysis, examination of the political economy and the study of social media and not overlook the situation in Central and Eastern European countries.

(ii) What is the role of the formal and informal institutions in tackling the COVID19 crisis? When scholars address this question, they should explore political stances towards the environmental crisis.

(iii) What are the challenges facing European politics with respect to populism or anti-populism discourses?

(iv) What are the major immigration flows (origin and destination) and the policies to deal with these flows? Empirical research should evaluate government responses across Europe and possible joint action.

(v) What will the nature of the rural/urban divide be in future politics? Research in this area should also consider various levels of government (local, regional and global).

(vi) How do nations view the future of the European Union and global governance? 
(vii) How do informal institutions evolve? What is their relationship with government formal institutions?

This list contains merely a small number of questions that scholars may wish to address. What does seem relevant is the need to consider current challenges in relation to gender, climate change, multiculturalism and the future role of Europe in multilateral relations. EPS must continue to provide frameworks for a wide readership consisting of journalists, lobbyists, politicians and electoral analysts to help them interpret political processes. It can also ensure that researchers apply quantitative and qualitative methods effectively to understand or anticipate electoral perceptions or constitutional crises.

Acknowledgements This research benefitted from: (i) grants RTI2018-093791-B-C21 and RTI2018093791-B-C22 funded by Ministry of Science and Innovation and ERDF. (ii) GV063/19 by Generalitat Valenciana.

\section{References}

Ahn, M., and S. Bretschneider. 2011. Politics of E-Government: E-Government and the Political Control of Bureaucracy. Public Administration Review 71 (3): 414-424.

Bach, T., G. Hammerschmid, and L. Löffler. 2020. More Delegation, More Political Control? Politicization of Senior-Level Appointments in 18 European Countries. Public Policy and Administration 35 (1): 3-23.

Bates, S., and H. Savigny. 2015. Introduction: Women in European Political Science. European Political Science 14 (2): 75-78.

Bates, S., L. Jenkins, and Z. Pflaeger. 2012. Women in the Profession: The Composition of UK Political Science Departments by Sex. Politics 32 (3): 139-152.

Bobba, G. 2019. Social Media Populism: Features and 'Likeability' of Lega Nord Communication on Facebook. European Political Science 18 (1): 11-23.

Bornmann, L., and R. Mutz. 2015. Growth Rates of Modern Science: A Bibliometric Analysis Based on the Number of Publications and Cited References. Journal of the Association for Information Science and Technology 66 (11): 2215-2222.

Bühlmann, M., W. Merkel, L. Müller, and B. Weßels. 2012. The democracy barometer: a new instrument to measure the quality of democracy and its potential for comparative research. European Political Science 11 (4): 519-536.

Burstein, P. 2010. Public Opinion, Public Policy, and Democracy. In Handbook of politics Handbooks of Sociology and Social Research, ed. K.T. Leicht and J.C. Jenkins, 63-79. New York: Springer. https ://doi.org/10.1007/978-0-387-68930-2_4.

Cassani, A., and L. Tomini. 2020. Reversing Regimes and Concepts: From Democratization to Autocratization. European Political Science 19 (2): 272-287.

Chao, C., J. Yang, and W. Jen. 2007. Determining Technology Trends and Forecasts of RFID by a Historical Review and Bibliometric Analysis from 1991 to 2005. Technovation 27 (5): 268-279.

Chiu, W., and Y. Ho. 2007. Bibliometric Analysis of Tsunami Research. Scientometrics 73 (1): 3-17.

Dahlström, C., and M. Holmgren. 2019. The Political Dynamics of Bureaucratic Turnover. British Journal of Political Science 49 (3): 823-836.

De Bakker, F., P. Groenewegen, and F. Den Hond. 2005. A bibliometric analysis of 30 years of research and theory on corporate social responsibility and corporate social performance. Business \& Society 44 (3): 283-317.

Donnelly, J. 2020. International Human Rights. London: Routledge.

Evans, E., and F. Amery. 2016. Gender and Politics in the UK: Banished to the Sidelines. European Political Science 15 (3): 314-321. 
Garand, J., and M. Giles. 2003. Journals in the Discipline: A Report on a New Survey of American Political Scientists. Political Science and Politics 36 (02): 293-308.

Giles, M., and J. Garand. 2007. Ranking Political Science Journals: Reputational and Citational Approaches. PS: Political Science \& Politics 40 (04): 741-751.

Gratton, G., and B. Lee. 2020. Liberty, Security, and Accountability: The Rise and Fall of Illiberal Democracies. SSRN Electronic Journal. https://doi.org/10.2139/ssrn.3704156.

Heck, J., and W. Bremser. 1986. Six Decades of the Accounting Review: A Summary of Author and Institutional Contributors. Accounting Review [online] 61 (4): 735-744.

Heise, M. 2002. The past, present, and future of empirical legal scholarship: Judicial decision making and the new empiricism. Cornell Law Faculty Publications. Paper 733. Available at https://scholarshi p.law.cornell.edu/facpub/733/

Helbling, M., L. Bjerre, F. Römer, and M. Zobel. 2017. Measuring Immigration Policies: The IMPIC Database. European Political Science 16 (1): 79-98.

Hix, S. 2004. A Global Ranking of Political Science Departments. Political Studies Review 2 (3): 293-313.

Howell, S., and C. Day. 2000. Complexities of the Gender Gap. The Journal of Politics 62 (3): 858-874.

Huggins, R., D. Prokop, and P. Thompson. 2019. Universities and Open Innovation: The Determinants of Network Centrality. The Journal of Technology Transfer 45 (3): 718-757.

Johnson, J., H. Reynolds, and J. Mycoff. 2015. Political Science Research Methods. Washington DC: Cq Press.

Kaufmann, K. 2006. The Gender Gap. PS Political Science \& Politics 39 (03): 447-453.

Kellstedt, P., D. Peterson, and M. Ramirez. 2010. The Macro Politics of a Gender Gap. Public Opinion Quarterly 74 (3): 477-498.

Kessler, M. 1963. An Experimental Study of Bibliographic Coupling Between Technical Papers (Corresp.). IEEE Transactions on Information Theory 9 (1): 49-51.

Landström, H., G. Harirchi, and F. Åström. 2012. Entrepreneurship: Exploring the Knowledge Base. Research Policy 41 (7): 1154-1181.

Leblang, D., W. Milner, and S. Poe. 1999. Security Rights, Subsistence Rights and Liberties: A Theoretical Survey of the Empirical Landscape. Human Rights Quarterly 21 (2): 403-443.

López-Rubio, P., N. Roig-Tierno, and A. Mas-Tur. 2020. Regional Innovation System Research Trends: Toward Knowledge Management and Entrepreneurial Ecosystems. International Journal of Quality Innovation. https://doi.org/10.1186/s40887-020-00038-X.

Mas-Tur, A., N.M. Modak, J.M. Merigó, N. Roig-Tierno, M. Geraci, and V. Capecchi. 2019. Half a Century of Quality \& Quantity: A Bibliometric Review. Quality \& Quantity 53 (2): 981-1020.

Meier, K., and L. O’Toole. 2006. Political Control Versus Bureaucratic Values: Reframing the Debate. Public Administration Review 66 (2): 177-192.

Mendelberg, T., C. Karpowitz, and J. Oliphant. 2014. Gender Inequality in Deliberation: Unpacking the Black Box of Interaction. Perspectives on Politics 12 (1): 18-44.

Møller, J., and S. Skaaning. 2013. Autocracies, Democracies, and the Violation of Civil Liberties. Democratization 20 (1): 82-106.

Mora, L., R. Bolici, and M. Deakin. 2017. The First Two Decades of Smart-City Research: A Bibliometric Analysis. Journal of Urban Technology 24 (1): 3-27.

Nai, A. 2019. Disagreeable Narcissists, Extroverted Psychopaths, and Elections: A New Dataset to Measure the Personality of Candidates Worldwide. European Political Science 18 (2): 309-334.

Narin, F. 1976. Evaluative Bibliometrics. Springfield: U.S. Department of Commerce. National Technical Information Service.

Oztig, L., and M. Donduran. 2020. Failed Coups, Political Survival, and Civil Liberties Restrictions in Nondemocratic Regimes. The Social Science Journal. https://doi.org/10.1080/03623 319.2020.1827686.

Podsakoff, P., S. MacKenzie, N. Podsakoff, and D. Bachrach. 2008. Scholarly Influence in the Field of Management: A Bibliometric Analysis of the Determinants of University and Author Impact in the Management Literature in the Past Quarter Century. Journal of Management 34 (4): 641-720.

Salgado, S. 2019. Where's Populism? Online Media and the Diffusion of Populist Discourses and Styles in Portugal. European Political Science 18 (1): 53-65.

Sarin, S., C. Haon, M. Belkhouja, A. Mas-Tur, N. Roig-Tierno, T. Sego, A. Porter, J. Merigó, and S. Carley. 2020. Uncovering the Knowledge Flows and Intellectual Structures of Research in Technological Forecasting and Social Change: A Journey Through History. Technological Forecasting and Social Change 160: 120210. 
Schneider, J. 2009. An Outline of the Bibliometric Indicator Used for Performance-Based Funding of Research Institutions in Norway. European Political Science 8 (3): 364-378.

Shor, E., J. Charmichael, J. Nazif Munoz, J. Shandra, and M. Schwartz. 2014. Terrorism and State Repression of Human Rights: A Cross-National Time-Series Analysis. International Journal of Comparative Sociology 55 (4): 294-317.

Sivertsen, G. 2006. A bibliometric model for performance-based budgeting of research institutions'. In Book of abstracts, 9th international science and technology indicators conference, 7-9 September 2006, ed. K. Debackere and W. Glänzel, 133-135. Leuven: KatholiekeUniversiteit.

Stavrakakis, Y., and G. Katsambekis. 2019. The Populism/Anti-populism Frontier and Its Mediation in Crisis-ridden Greece: From Discursive Divide to Emerging Cleavage? European Political Science 18 (1): 37-52.

Stimson, J. 2019. Public Opinion in America: Moods, cycles, and swings. New York: Routledge.

Stockemer, D., A. Blair, and E. Rashkova. 2020. The Distribution of Authors and Reviewers in EPS. European Political Science 19 (3): 401-410.

Suominen, A., M. Seppänen, and O. Dedehayir. 2019. A Bibliometric Review on Innovation Systems and Ecosystems: A Research Agenda. European Journal of Innovation Management 22 (2): 335-360.

Teele, D., and K. Thelen. 2017. Gender in the Journals: Publication Patterns in Political Science. PS: Political Science \& Politics 50 (02): 433-447.

Tur-Porcar, A., A. Mas-Tur, J. Merigó, N. Roig-Tierno, and J. Watt. 2018. A Bibliometric History of the Journal of Psychology Between 1936 and 2015. The Journal of Psychology 152 (4): 199-225.

van Eck, N. and Waltman, L. 2007. VOS: A New Method for Visualizing Similarities Between Objects. Studies in Classification, Data Analysis, and Knowledge Organization: 299-306.

van Eck, N., L. Waltman, E. Noyons, and R. Buter. 2010. Automatic Term Identification for Bibliometric Mapping. Scientometrics 82 (3): 581-596.

Publisher's Note Springer Nature remains neutral with regard to jurisdictional claims in published maps and institutional affiliations.

Francisco Mas-Verdu Professor of Economics at the Universitat Politècnica de València, Spain; his research is focused on innovation and regional development

Jose-Maria Garcia-Alvarez-Coque Professor of Economics, Universitat Politècnica de València, Spain; President of the Spanish Association of Agricultural Economists (2001-2007); current interest: international economics and development policies

Paula Andrea Nieto-Aleman Ph.D. in Agrifood Economy at the Universitat Politècnica de València, Spain; current main interest: territorial development and peace process

Norat Roig-Tierno Associated Professor in Applied Economics at the Universitat Politècnica de València, Spain; current interest: use and application of Qualitative Comparative analysis (QCA) to the study of economic activities 